\title{
Perbaikan Kualitas Air Yang Memiliki Konsentrasi Besi (Fe) Tinggi Menggunakan Single Tray Aerator
}

\author{
Bagus Putro Budi Utomo ${ }^{1 *}$, Ahmad T. Yuliansyah ${ }^{2}$, Agus Prasetya ${ }^{3}$ \\ 1*Magister Teknik Sistem, Fakultas Teknik, Universitas Gadjah Mada \\ ${ }^{2,3}$ Departemen Teknik Kimia, Fakultas Teknik, Universitas Gadjah Mada \\ Surel: ${ }^{1 *}$ bagus.putro.b@mail.ugm.ac.id, ${ }^{2}$ atawfieq@ugm.ac.id, ${ }^{3}$ aguspras@ugm.ac.id
}

\section{ABSTRAK}

Air adalah salah satu sumber daya alam yang yang sangat penting bagi kehidupan manusia. Air tanah, yang menjadi sumber air di masyarakat, sering didapatkan mengandung konsentrasi besi (Fe) yang melebihi baku mutu. Air tersebut ditandai dengan adanya flek-flek warna kuning kecoklatan yang terdapat pada bak air atau perabotan yang berhubungan dengan air. Air yang mempunyai konsentrasi besi tinggi dapat menyebabkan gangguan kesehatan, misalnya: merusak dinding usus, iritasi pada mata dan kulit. Single tray aerator merupakan teknologi pengolahan air yang sederhana dan mudah dalam pengoperasiannya, sehingga dapat menjadi jawaban akan masalah air ini. Air yang telah diolah diharapkan dapat dimanfaatkan sebagaimana mestinya dan tidak berdampak buruk bagi manusia. Penilitian ini mencoba mencari media terbaik pada tray guna menurunkan konsentrasi besi pada air tanah. Terdapat 3 variasi media yang dilakukan pada peneilitian ini yaitu tanpa media, media zeolit dan media kerikil. Proses pengambilan sampel air dilakukan pada menit ke 5, 10, 15 dan 20. Didapatkan hasil dari penelitian ini bahwa kualitas air sebelum diolah adalah $\mathrm{Fe}=1,65 \mathrm{mg} / \mathrm{l}$. Data yang didapatkan 5 menit merupakan waktu efektif pada proses penurunan $\mathrm{Fe}$ pada air baku. Penggunaan single tray aerator tanpa media setelah diolah didapatkan hasil $\mathrm{Fe}=1,23 \mathrm{mg} / \mathrm{l}$, media kerikil didapatkan hasil $\mathrm{Fe}=1,19 \mathrm{mg} / \mathrm{l}$, dan percobaan terakhir menggunakan media zeolit didapatkan hasil $\mathrm{Fe}=1,07$ $\mathrm{mg} / \mathrm{l}$. Zeolit merupakan media terbaik pada penelitian ini dalam menurunkan konsentrasi Fe. Hasil pengolahan dari semua jenis variasi pada penelitian ini belum memenuhi baku mutu.

\section{Kata kunci}

Air,

Besi $(\mathrm{Fe})$,

Single tray aerator

\section{PENDAHULUAN}

Air adalah salah satu sumber daya alam yang yang sangat penting bagi kehidupan manusia. sel hidup misalnya, baik tumbuhtumbuhan ataupun hewan, sebagian besar tersusun oleh air, yaitu lebih $75 \%$ isi sel tumbuh-tumbuhan atau lebih dari $67 \%$ isi sel hewan, tersusun oleh air ${ }^{[1]}$. Sumber air baku untuk air bersih secara garis besar dapat digolongkan menjadi 4 (empat) bagian yaitu : air laut, air atmosfir atau air hujan, air permukaan dan air tanah yang masing-masing mempunyai karakteristik yang berbeda-beda ditinjau dari segi kualitas dan kuantitasnya ${ }^{[2]}$. Air Tanah adalah air yang terdapat dalam lapisan tanah atau batuan di bawah 
permukaan $\operatorname{tanah}^{[3]}$. Air tanah yang sering didapatkan mempunyai kandungan zat besi (Fe) dan Mangan (Mn) cukup besar ${ }^{[4]}$. Masalah tingginya zat besi dan mangan di dalarn air, lebih sering terjadi jika sumber air baku yang digunakan berasal dari air tanah ${ }^{[5]}$. Flek-flek yang terdapat di pinggir sumur seperti warna coklat yang mengindikasikan adanya kandungan zat $\mathrm{Fe}$ (besi) dan berwarna kehitam-hitaman yang mengindikasikan adanya kandungan zat Mn (mangan ${ }^{[6]}$.

Joko $^{[7]}$ menyatakan konsentrasi besi (Fe) terlarut dalam air yang melebihi batas baku mutu akan menyebabkan berbagai masalah seperti gangguan teknis, misalnya: mengotori bak, wastafel, kloset, korosif pada pipa yang mengakibatkan pembatuan, dan gangguan fisik, misalnya: timbulnya warna, bau, dan rasa, serta menyebabkan gangguan kesehatan, misalnya: merusak dinding usus, iritasi pada mata dan kulit. Guna menghindari dampak negatif akibat kandungan Fe pada air maka perlu dilakukan pengolahan air terlebih dahalu sebelum dikonsumsi. Besi yang terlarut di air dapat dihilangkan dengan cara aerasi, yaitu mengontakkan air dengan oksigen sehingga mangan dan besi mengalami oksidasi yang menyebakan mangan dan besi dapat diendapakan secara gravitasi. Alat yang digunakan untuk aerasi disebut dengan aerator. Pada penelitian tentang menurunkan konsentrasi $\mathrm{Fe}$ menggunakan alat single tray aerator.

\section{METODE PENELITIAN}

\section{Alat dan Bahan}

Alat yang digunakan terdiri dari :

1. Gelas ukur $1 \mathrm{~L}$

2. Stopwatch

3. Botol sampel

4. Tandon air baku

5. Beaker glass

6. Pompa air

7. Terminal listrik

8. Gergaji

9. Bor

10. Kran air

11. Kunci inggris

12. Pompa air
Bahan yang digunakan sebagai berikut :

1. Air baku

2. Batu krikil

3. Zeolit

4. Pipa PVC $1 / 2 \otimes$ dan $3 / 4 Q$

5. Nampan persegi panjang

6. Mor dan baut

\section{Gambar Alat}

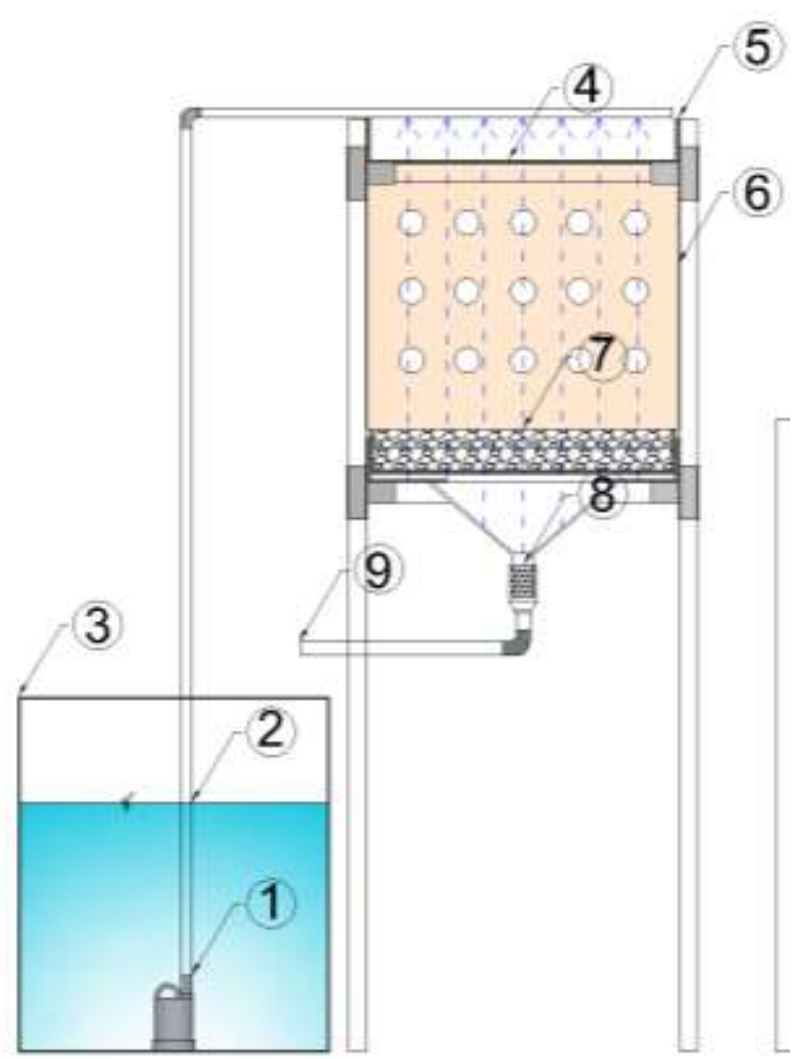

Gambar 1. Single Tray Aerator

\section{Metode Pengumpulan Data}

Data yang dikumpulkan meliputi :

1. Data Primer; adalah data yang didapatkan secara langsung di lapangan dalam hal ini hasil analisis kualitas air di laboratorium 
sebelum dan sesudah diolah dan juga bisa pengamatan selama penelitian berlangsung.

2. Data Skunder; merupakan data-data yang didapatkan melalui studi literatur yang mendukung keberhasilan penelitian yang didapatkan melalui media cetak amaupun elektronik.

\section{Proses Penelitian}

1. Tahap Persiapan

Penelitian ini terdapat beberapa tahap, yang pertama yaitu pengumpulan data terkait dengan penelitian dan pengumpulan bahan-bahan serta alat yang dibutuhkan dalam penelitian. Air baku yang digunakan merupakan air yang telah ditambahkan konsentrasi Fe dengan penambahan bahan kimia sebesar untuk Fe dan 15,32 mg/lt. Pembuatan air baku buatan ini menggunakan $\mathrm{FeSO}_{4} \cdot 7 \mathrm{H}_{2} \mathrm{O}$ untuk penambahan konsentrasi $\mathrm{Fe}$. Pengaturan konsentrasi $\mathrm{Fe}$ ini dilakukan guna penyeragaman air baku yang akan diolah. Sehingga pada penelitian ini dapat diketahui performa alat dalam melakukan penurunan konsentrasi Fe pada air baku. Berikut diagram alir percobaan ini dimulai dari awal hingga analisis akhir dapat dilihat pada gambar 2 berikut.

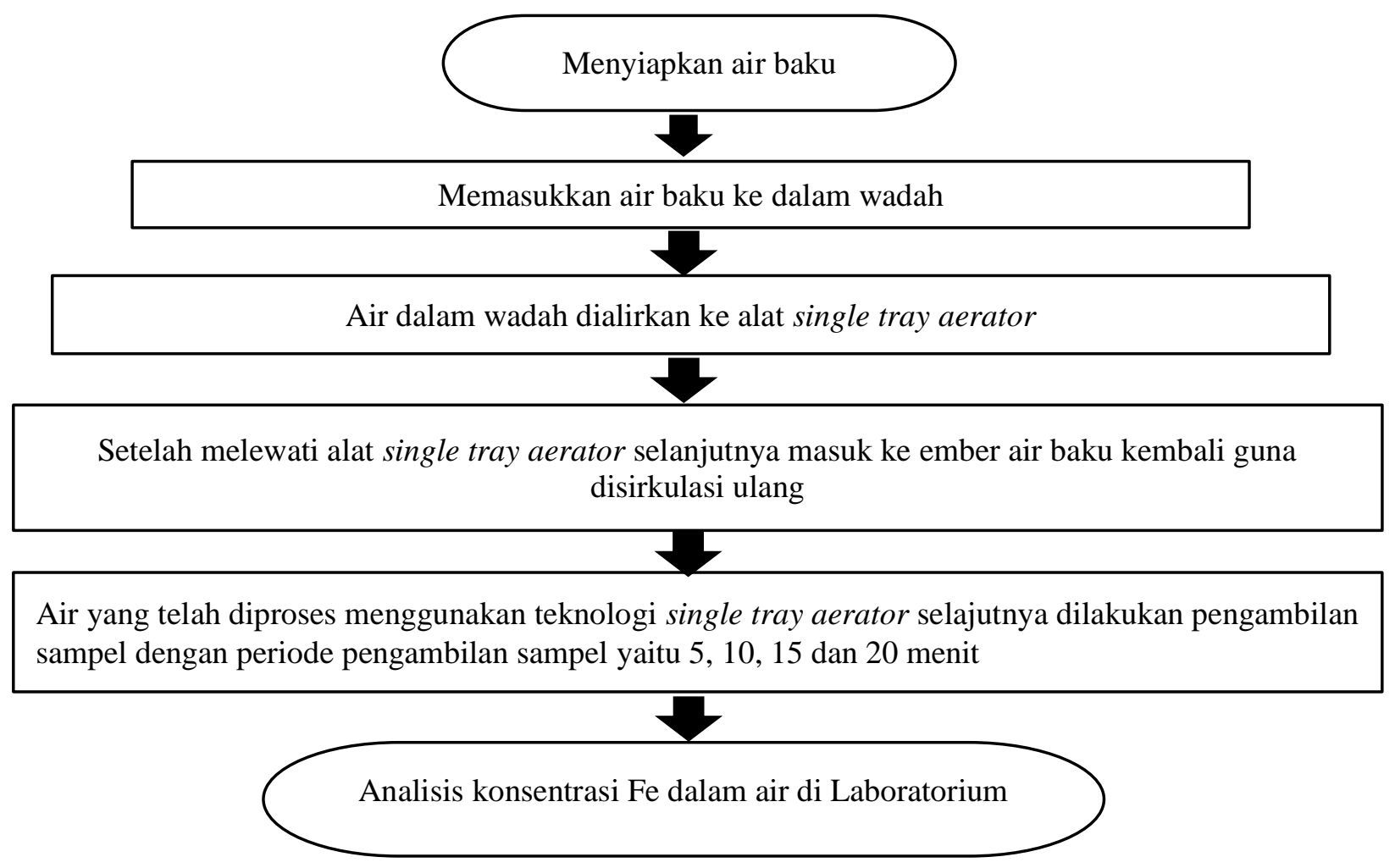

Gambar 2. Diagram alir percobaan

\section{Persiapan Alat}

Pada tahap persiapan alat ini terdiri dari single tray aerator, pompa air, wadah air baku, stopwatch, dan botol sampel.

\section{Proses Percobaan}

Percobaan dilakukan dengan prosedur berikut

1. Menyiapkan wadah dengan kapasitas 40 liter guna menampung 30 liter air baku yang telah dibuat.
2. Menyiapkan alat single tray aerator kemudian air baku dimasukkan ke dalam wadah.

3. Mengatur jarak antar tray dan distributor dengan jarak $30 \mathrm{~cm}$.

4. Meletakkan media pada tray dengan ketebalan $3 \mathrm{~cm}$.

5. Mengoprasikan pompa guna mendistribusikan air baku ke tray.

6. Melakukan pengambilan sampel untuk satu siklus percobaan dilakukan pada 
waktu yang telah ditentukan yaitu setiap 5 menit, 10 menit, 15 menit dan 20 menit.

7. Sampel yang diambil kemudian di bawah ke laboratorium guna dianalisis kandungan $\mathrm{Fe}$ yang terdapat dalam sampel.

\section{Analisis Fe (Besi)}

Analisis $\mathrm{Fe}$ yang dilakukan guna mengetahui konsentrasi Fe yang tedapat dalam air baku setelah diolah. Analisis Fe dilakukan di laboratorium Sekolah Menengah Teknik Industri (SMTI) dengan menggunakan alat AAS.

\section{HASIL DAN PEMBAHASAN}

Berdasarkan dari hasil penelitian, didapatkan bahwa konsentrasi $\mathrm{Fe}$ pada air baku adalah 1,65 mg/l. Konsentrasi parameter tersebut melebihi baku mutu yang telah ditetapkan oleh Peraturan Menteri Kesehatan No. 32 Tahun 2017 tentang Setandar Baku Mutu Kesehatan Lingkungan Dan Persyaratan Kesehatan Air Untuk Keperluar Higiene Sanitasi, Kolam Renang, Solus Per Aqua, dan pemandian Umum yang mensyaratkan maksimal kandungan Fe 1 mg/l.
Dalam usaha memperbaiki kualias sumber daya air dengan menggunakan teknologi single tray aerator. Peneleitian ini akan dilakukan pengaturan jarak antara distributor air dan tray dengan jarak $30 \mathrm{~cm}$. Kemudian, dilakukan variasi media pada tray. Variasi media yang dilakukan adalah penambahan media zeolit media kerikil dan tanpa media pada tray.

Percobaan pertama dilakukan dengan jarak distributor dan tray sejauh $30 \mathrm{~cm}$ dengan keadaan tray tidak diberikan tambahan media. Berikut hasil analisis laboratorium untuk percobaan pertama dapat dilihat pada tabel 1 .

Tabel 1. Percobaan Pertama

\begin{tabular}{cccc}
\hline Menit & Konsentrasi Fe & Baku mutu & Satuan \\
\hline 0 & 1,65 & 1 & $\mathrm{mg} / \mathrm{l}$ \\
5 & 1,23 & 1 & $\mathrm{mg} / \mathrm{l}$ \\
10 & 1,32 & 1 & $\mathrm{mg} / \mathrm{l}$ \\
15 & 1,38 & 1 & $\mathrm{mg} / \mathrm{l}$ \\
20 & 1,32 & 1 & $\mathrm{mg} / \mathrm{l}$ \\
\hline
\end{tabular}

Tabel 1 menunjukkan tren yang cukup baik pada removal Fe sejak menit ke-0 sampai ke-20 (Gambar 3).

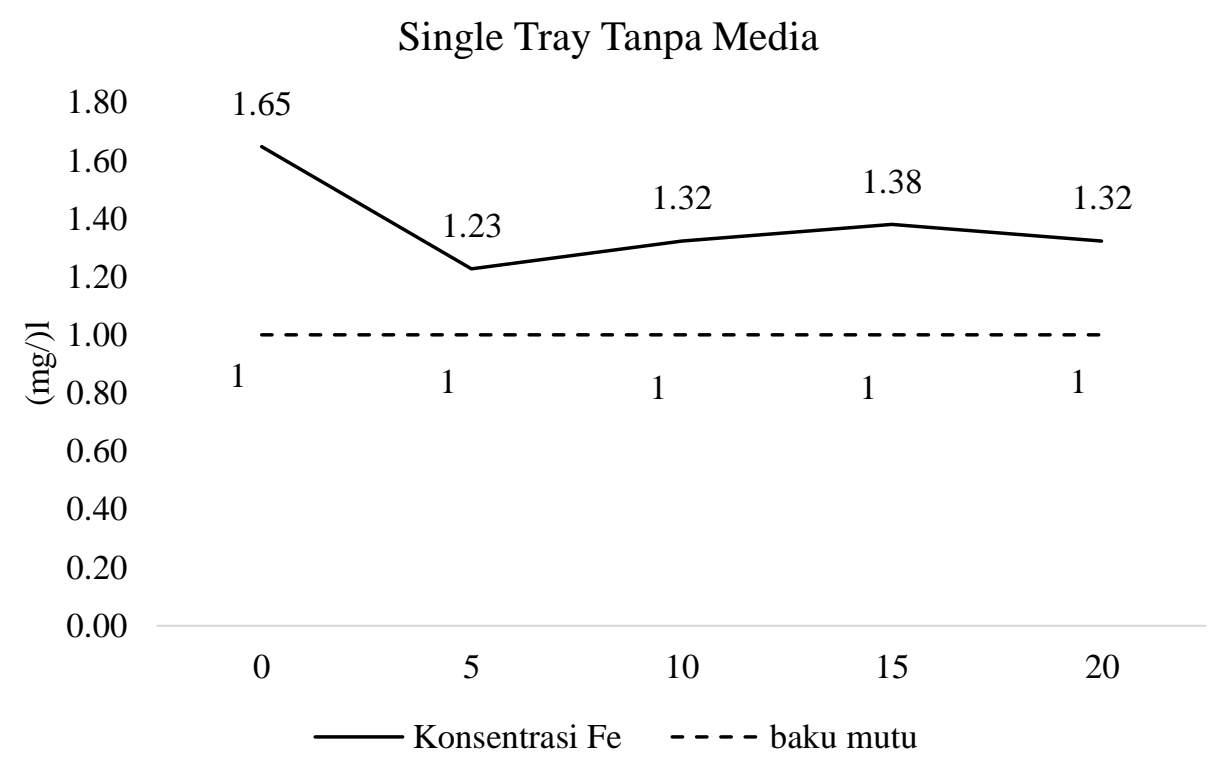

Gambar 3. Percobaan Pertama

Pada percobaan ini dapat diketahui bahwa kemampuan removal yang cukup efektif pada 5 menit. Selanjutnya Percobaan kedua dilakukan dengan jarak distributor dan tray sejauh $30 \mathrm{~cm}$ dan tray diberikan 
tambahan media kerikil. Hasil analisis laboratorium ditunjukkan pada Tabel 2.

Tabel 2. Percobaan Kedua

\begin{tabular}{cccc}
\hline Menit & Konsentrasi Fe & Baku mutu & Satuan \\
\hline 0 & 1,65 & 1 & $\mathrm{mg} / \mathrm{l}$ \\
5 & 1,19 & 1 & $\mathrm{mg} / \mathrm{l}$ \\
10 & 1,36 & 1 & $\mathrm{mg} / \mathrm{l}$ \\
15 & 1,27 & 1 & $\mathrm{mg} / \mathrm{l}$ \\
20 & 1,23 & 1 & $\mathrm{mg} / \mathrm{l}$ \\
\hline
\end{tabular}

Pada tabel di atas dapat dilihat bahwa removal Fe mulai dari menit ke 0 sampai menit ke 20 menunjukkan tren yang cukup baik. Diketahui konsentrasi $\mathrm{Fe}$ pada saat diolah menggunakan single tray aerator untuk menit ke 0 konsentrasi $\mathrm{Fe}=1,65 \mathrm{mg} / \mathrm{l}$, kemudian pada menit ke 5 konsentrasi $\mathrm{Fe}=$ $1,19 \mathrm{mg} / \mathrm{l}$, menit ke 10 konsentrasi $\mathrm{Fe}=1,36$ $\mathrm{mg} / \mathrm{l}$, menit ke 15 konsentrasi $\mathrm{Fe}=1,27 \mathrm{mg} / \mathrm{l}$ dan menit ke 20 konsentrasi $\mathrm{Fe}=1,23 \mathrm{mg} / \mathrm{l}$. Untuk lebih jelasnya dapat dilihat pada gambar 4 berikut ini.

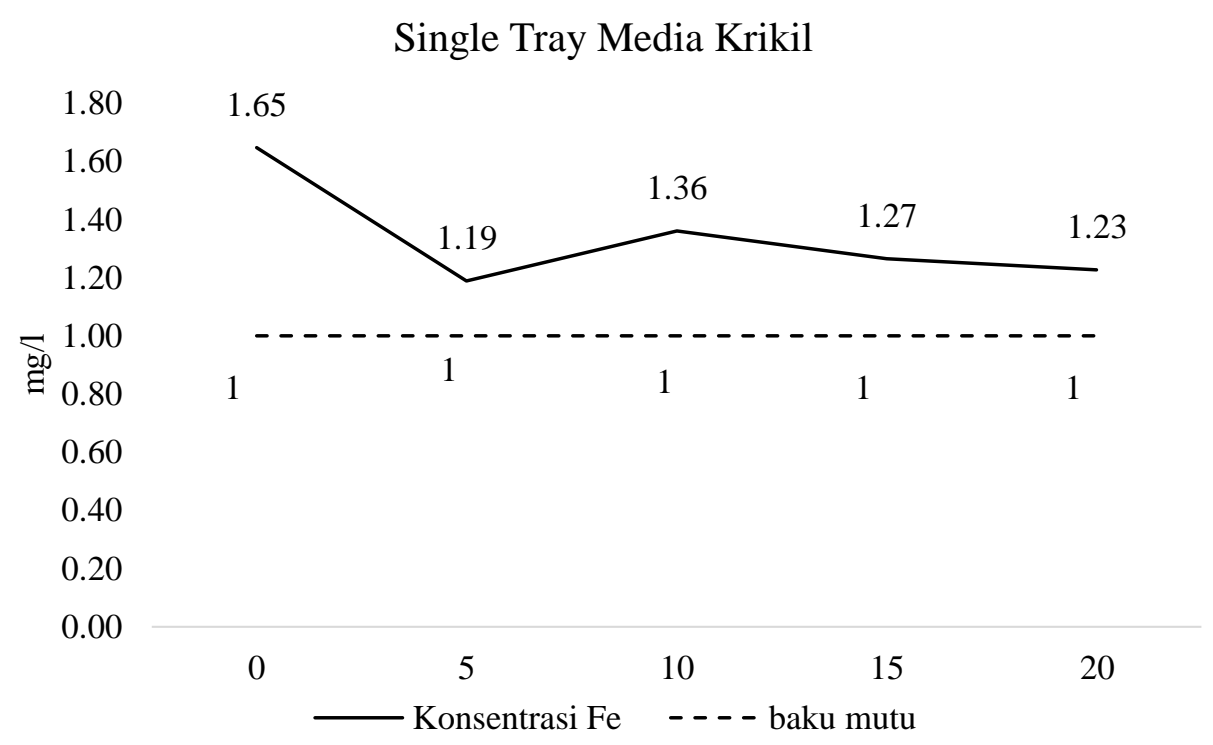

Gambar 4. Percobaan Kedua

Pada percobaan kedua diketahui kemampuan removal yang cukup efekti pada 5 menit. Percobaan ketiga dilakukan dengan jarak distributor dan tray sejauh $30 \mathrm{~cm}$ dengan tambahan media zeolit pada tray. Hasil analisis laboratorium untuk percobaan ketiga dapat dilihat pada tabel 3 .

\section{Tabel 3. Percobaan Ketiga}

\begin{tabular}{cccc}
\hline Menit & Konsentrasi Fe & Baku mutu & Satuan \\
\hline 0 & 1,65 & 1 & $\mathrm{mg} / \mathrm{l}$ \\
5 & 1,07 & 1 & $\mathrm{mg} / \mathrm{l}$ \\
10 & 1,25 & 1 & $\mathrm{mg} / \mathrm{l}$ \\
15 & 1,25 & 1 & $\mathrm{mg} / \mathrm{l}$ \\
20 & 1,23 & 1 & $\mathrm{mg} / \mathrm{l}$ \\
\hline
\end{tabular}

Pada tabel di atas dapat dilihat bahwa removal Fe mulai dari menit ke 0 sampai menit ke 20 menunjukkan tren yang cukup baik. Diketahui konsentrasi $\mathrm{Fe}$ pada saat diolah menggunakan single tray aerator untuk menit ke 0 konsentrasi $\mathrm{Fe}=1,65 \mathrm{mg} / \mathrm{l}$, kemudian pada menit ke 5 konsentrasi $\mathrm{Fe}=$ $1,07 \mathrm{mg} / \mathrm{l}$, menit ke 10 konsentrasi $\mathrm{Fe}=1,25$ $\mathrm{mg} / \mathrm{l}$, menit ke 15 konsentrasi $\mathrm{Fe}=1,25 \mathrm{mg} / \mathrm{l}$ dan menit ke 20 konsentrasi $\mathrm{Fe}=1,23 \mathrm{mg} / \mathrm{l}$ (Gambar 5). 


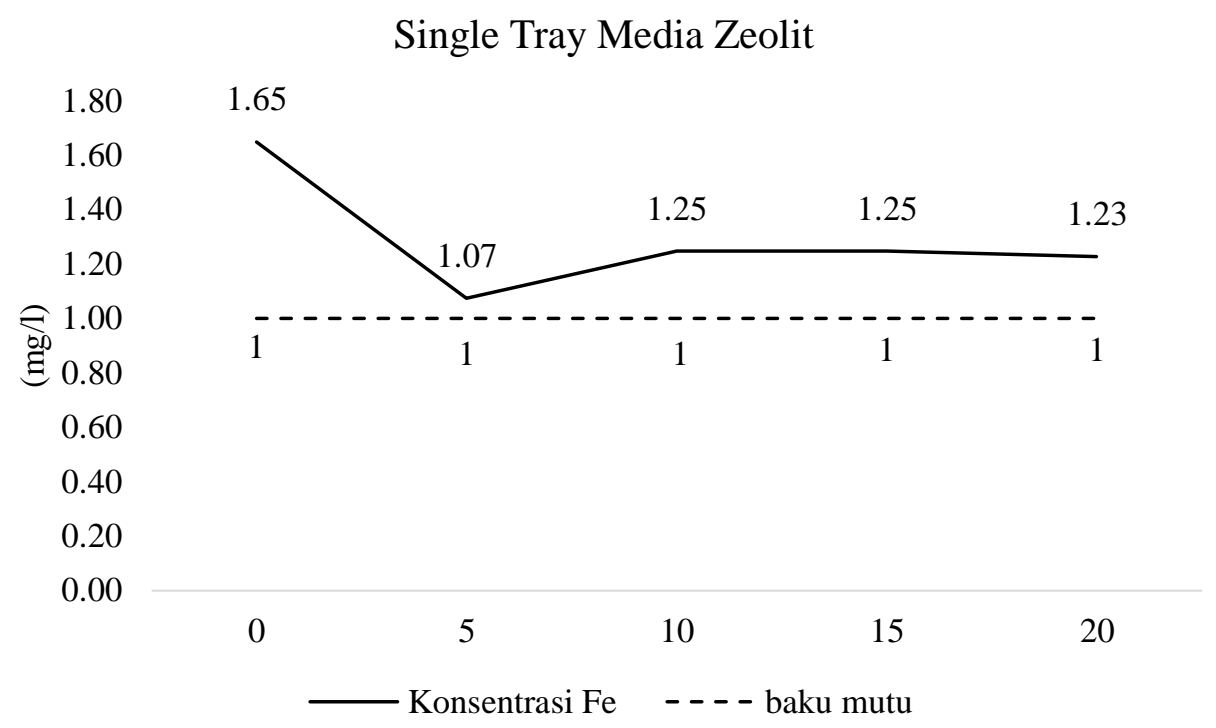

Gambar 5. Percobaan Ketiga

Dari percobaan ketiga dapat diketahui bahwa kemampuan removal yang cukup efekti pada 5 menit. Berdasarkan dari data yang ditampilkan di atas mengenai hasil penelitian Penurunan kosentrasi $\mathrm{Fe}$ (besi) pada air baku, penurunan konstrasi $\mathrm{Fe}$ tertinggi berlangsung pada 5 menit pertama hal ini didapatkan dari ketiga jenis variasi penelitian. Hal tersebut dapat terjadi karna air mempunyai tingkat kejenuhan dalam melarutkan oksigen admosfer menjadi oksigen terlarut dalam air.

Hasil dari pengolahan dengan 5 menit aerasi tanpa menggunakan media pada tray, yang awalnya konsentrasi $\mathrm{Fe}=1,65 \mathrm{mg} / \mathrm{l}$ menjadi 1,23 mg/l. Kemudian, pengolahan air dengan tray menggunakan media kerikil didapatkan hasil pada mulanya konsentrasi $\mathrm{Fe}$ $=1,65 \mathrm{mg} / \mathrm{l}$ setelah diolah didapatkan hasil $\mathrm{Fe}$ $=1,19 \mathrm{mg} / \mathrm{l}$. Pada percobaan terakhir, pengolahan air dengan tray aerator menggunakan media zeolit pada tray konsentrasi awal $\mathrm{Fe}=1,65$ kemudia setelah diolah selama 5 menit didapatkan hasil $\mathrm{Fe}=$ $1,07 \mathrm{mg} / \mathrm{l}$.

Pengolahan air menggunakan tray aerator dengan tambahan media kerikil lebih efektif dibanding dengan tanpa media, tapi media zeolit lebih efektif dalam menurunkan konsentrasi Fe pada air. Hal ini dapat terjadi karna penggunaan media baik itu kerikil ataupun zeolit dapat memperpanjang waktu kontak dan memperkecil butiran air sehingga memperbesar luas permukaan air yang kontak dengan udara. Media zeolit lebih efektif menurunkan konsntrasi $\mathrm{Fe}$ dibanding media kerikil hal ini dikarenakan, zeolit mempunyai kemampuan alami yaitu adsorbsi dan ion excenger. Hasil pengolahan dari semua jenis variasi pada penelitian ini belum memenuhi baku mutu, hal ini karna metode single tray aerator sebaiknya tidak dipadukan dengan unit filtasi agar Fe yang telah teroksidasi menjadi tidak terlarut dapat dipisahkan dari air hasil olahan.

\section{KESIMPULAN}

Dari penelitian ini dapat disimpulkan bahwa kemampuan removal Fe yang paling efektif pada waktu aerasi 5 menit. Teknologi single tray aerator tanpa tambahan media dengan lama aerasi 5 menit dapat menurunkan konsentrasi $\mathrm{Fe}=1,65 \mathrm{mg} / \mathrm{l}$ menjadi $1,23 \mathrm{mg} / \mathrm{l}$, media kerikil didapatkan hasil $\mathrm{Fe}=1,19 \mathrm{mg} / \mathrm{l}$, dan percobaan terakhir menggunakan media zeolit didapatkan hasil $\mathrm{Fe}=1,07 \mathrm{mg} / \mathrm{l}$. Zeolit merupakan media terbaik pada penelitian ini dalam menurunkan konsentrasi Fe. Hasil pengolahan dari semua jenis variasi pada penelitian ini belum memenuhi baku mutu.

\section{SARAN}

Penelitian memiliki kelemahan untuk itu disarankan untuk penelitian selanjutnya 
menggabungkan teknologi single tray aerator dengan teknologi filter.

\section{REFERENSI}

[1] Suriawiria, U., 2008, Mikrobiologi Air, Bandung, PT Alumni.

[2] Sutrisno, T. C., 2004, Teknologi Penyediaan Air Bersih, Jakarta, Rineka Cipta.

[3] Peraturan Menteri ESDM No. 15 tentang Penghematan Penggunaan Air Tanah.

[4] Badan Pengkajian dan Penerapan Teknologi, Pembuatan Filter Untuk Menghilangkan Zat Besi dan Mangan Di Dalam Air.

[5] Asmadi, K., Kasjono, H. S., 2011, Teknologi Pengolahan Air Minum.

[6] Delinatalis, 2015, Perbaikan Kualitas Air Sumur (Fe total dan Mn) Menggunakan Tray Aerator dan Filter di Dusun Kuwaru kecamatan Serandakan Kabupaten Bantul Yogyakarta, Yogyakarta, Institut Teknologi Yogyakarta.

[7] Joko T., 2010, Unit Produksi dalam Sistem Penyediaan Air Minum, Yogyakarta, Graha Ilmu. 